\title{
New Type of Preventable Death
}

\section{Takashi Ukai, MD}

Senior Consultant, Hyogo Emergency

Medical Center, Kobe, Hyogo, Japan

Correspondance:

Takashi Ukai, MD

Senior Consultant

Hyogo Emergency Medical Center

1-3-1, WakihamaKaigandori, Chuoku

Kobe, Hyogo 651-0073

Japan

E-mail: ukai-t@mxr.mesh.ne.jp

Keywords: deep vein thrombosis (DVT); evacuation center; preventable death; pulmonary embolism; shelter

Abbreviations:

DVT $=$ deep vein thrombosis

Web publication: 03 May 2005

\section{Dear Editor:}

The Niigata-Chuetsu earthquake, which hit the Niigata Prefecture of Japan on 23 October 2004, claimed 40 deaths. Of these victims, 27 were killed almost instantly by trauma, and 23 were killed by so-called disaster-related death. At least 11 people suffered from pulmonary embolism and five died within two weeks of the disaster. All of them had been using motor vehicles as their shelter, because the officially designated evacuation centers (gymnasiums) were too crowded. Many people thought that their small cars were more comfortable than the evacuation centers, that afforded very little privacy. Some preferred to stay outside of the buildings because of the repeated strong aftershocks. Although tents were distributed to the evacuees, it was too cold to stay in them at night.

Sudden death and illness by pulmonary embolism now is popularly known as "Economy Class Syndrome", as seating arrangements in economy class are too narrow for passengers to stretch their legs. The development of deep vein thrombosis (DVT) among people spending a long time crowded in their small cars is predicted easily.

Using ultrasonography, Dr. K. Hanzawa of Niigata University Medical School checked 69 evacuees who used their cars as shelter for $>3$ days and found DVT in 22 of them. Of these, three showed clinical symptoms of DVT. Elderly people were prone to restrain themselves from drinking water, as they hesitated to use the public toilet frequently. This also might be one of the causes of the high incidence of DVT.

Death by pulmonary embolism among evacuees in their cars must be a new type of preventable death that may be avoided by the public education and preparation of more comfortable evacuation environment. It may likely be seen in places other than a densely populated country like Japan.

\section{Measures of Effectiveness of Hospital Incident Command System Performance}

\author{
Jeffrey L. Arnold, MD; James Paturas, EMT-P; Ülkümen Rodoplu, MD
}

Keywords: effectiveness; emergency management; hospital emergency incident command system (HEICS); incident command system (ICS); performance; triage
Abbreviations:
HEICS = hospital emergency incident com- mand system
ICS = incident command system

Web publication: 03 May 2005

\section{Dear Editor:}

The article by Thomas, Hsu, Kim, et al entitled "The Incident Command System in Disasters: Evaluation Methods for a Hospital-based Exercise" in the January-February 2005 issue of Prebospital and Disaster Medicine raises important questions about what constitutes a relevant measure for hospital Incident Command System (ICS) performance in real or simulated emergencies or disasters. ${ }^{1}$ In this article, the authors suggest that the comparative time intervals to triage, treatment, or transportation are relevant measures of ICS performance in a hospital disaster exercise. Unfortunately, this study and its underlying assumptions have several important limitations.

A first concern is that the authors never define what they mean by a hospital ICS or show us the configuration of the one that they studied. This seems particularly important if we are to generalize their results to other settings. For example, the hospital ICS in this study does not appear to be the Hospital Emergency Incident Command System (HEICS), since its nomenclature is unique (e.g., "Staging Area Coordinator"), there is no report that job actions sheets were used, and unusual responsibilities are reported, such as the Incident Commander designating the triage 